\section{Special Thanks}

Dean of Students Office, York University Staf Association, Ron Stermac, CBC Television, Mark Smith, David Flaherty, Café de la Terrasse, Bill in Physical Plant and to Jocelyn for the last-minute welding.

\section{Our Next Production}

\section{EVERYMAN}

Directed by Skip Shand

November $6-10 \quad 8: 30 \mathrm{pm} \$ 3.00$

November 9

pay what you can
Student Theatre Projects Glendon College presents

\section{SEXUAL} PERVERSITY IN CHICAGO

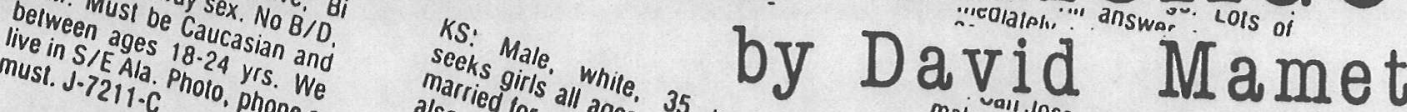

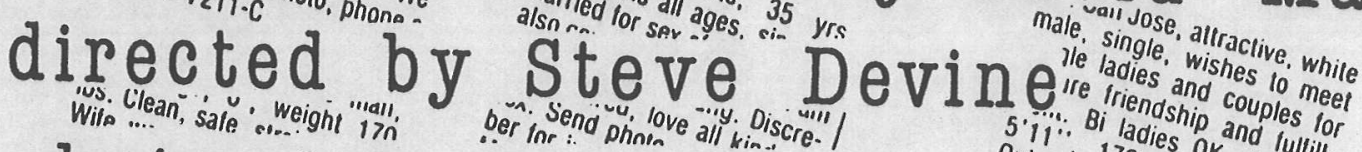

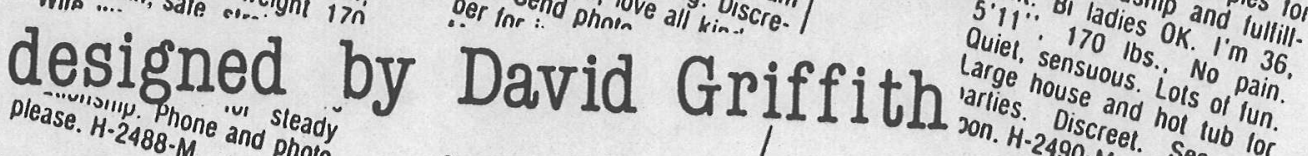

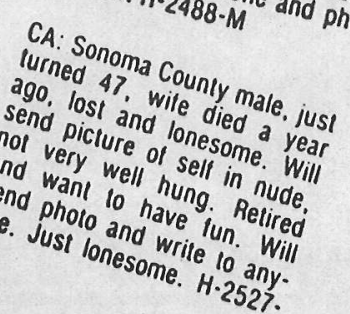

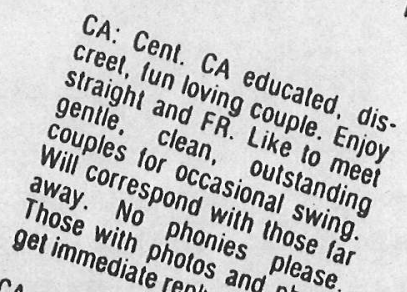
$C_{A}$ : Orang male. Orange Count race. age married or seeks while

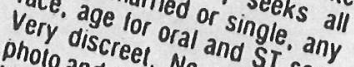
pholo and pheet. No and ST sex.

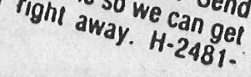

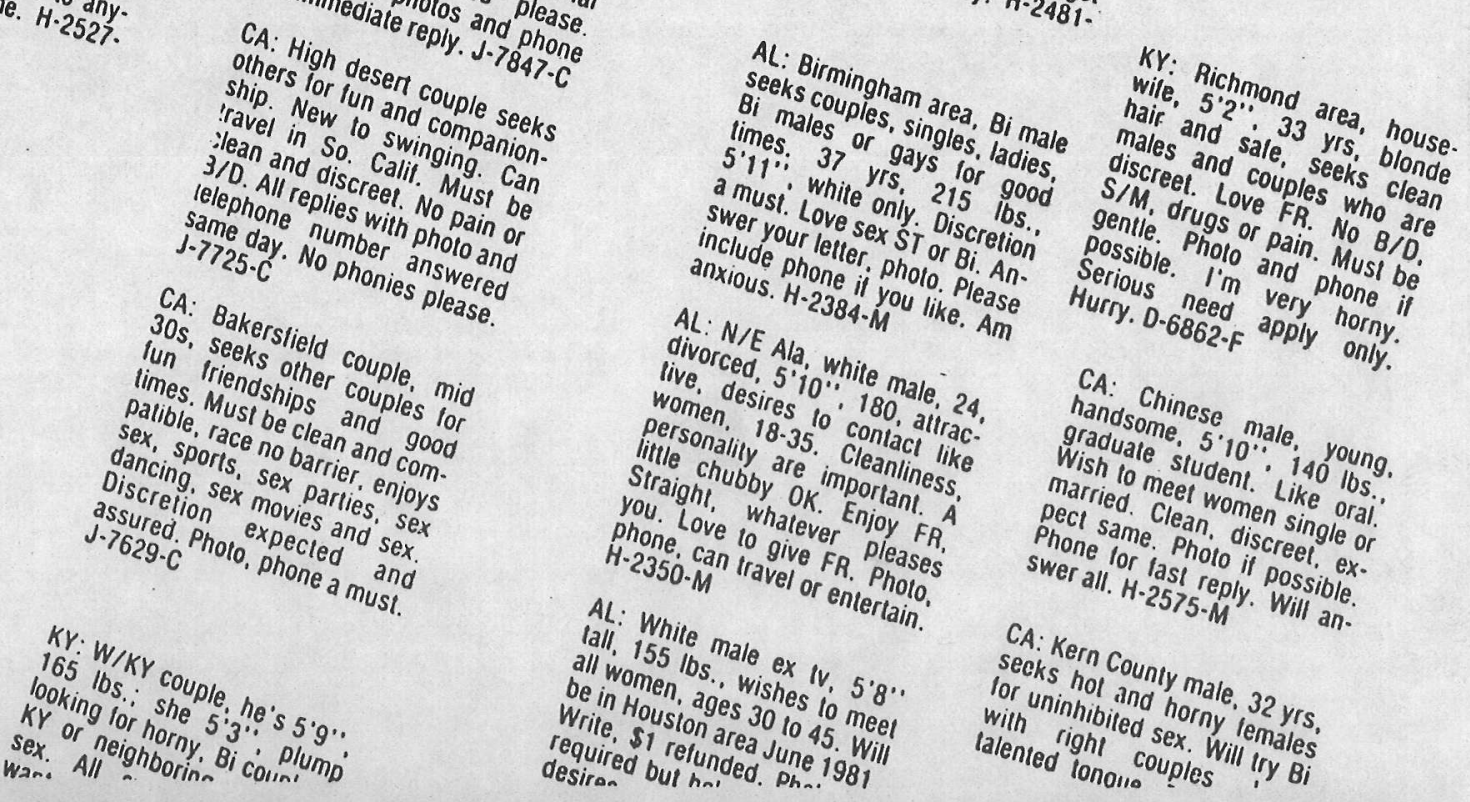


SEXUAL PERVE'RSITY IN CHICAGO

$$
\text { by David Mamet }
$$

Cast

$$
\begin{aligned}
& \text { Danny - David Perun } \\
& \text { Bernie - James Snetsinger } \\
& \text { Joan - Stephanie Kuntz } \\
& \text { Deborah - Denise Healey }
\end{aligned}
$$

Stage Manager - Meris Rognvaldson

Assistant Stage Manager - Rebekah Peever

Directed by Stephen Devine*

Sexual Perversity in Chicago will be presented without intermission. Patrons are reminded that smoking and cameras are not permitted in the theatre.

* By permission of Canadian Actors' Equity Association

\section{FOR "SEXUAL PERVERSITY IN CHICAGO"}

Production Manager - Christine Monteith Stage Designer - David Griffith Lighting Designer and

$$
\text { Technical Director - Moira Fox }
$$

Costume Mistress - Sondra Travis

Properties Mistress - Anastasia Kaunda

Sound - Andrea McCabe

Lighting Operator - Moira Fox

Set Construction - Tony Aiken, Ian Barr

Vez Pajkovic, Mike Tincombe, Robert Najm Peter Valks

Box Office Manager - Eunice Day

House Manager - Gail Commandant

\section{FOR ETUDES DRAMATIQUES/DRAMA STUDIES}

Coordinator - Robert Wallace

\section{FUR THEATRE GLENDON}

Technical Director - Stephen Devine Assistant Technical Director - Moira Fox (Ontario Career Action Program) 